\title{
Data Mining untuk Nasabah Bank Telemarketing Menggunakan kombinasi Algoritm Naïve Bayes Dan Algoritma Genetik
}

\author{
Ahmad Asifuddin Aqham, Kristoko Dwi Hartomo
}

Universitas Kristen Satya Wacana, Salatiga,50711,Indonesia

\section{KEYWORDS}

telemarketing, nä̈ve bayes, algortima genetika

\section{CORRESPONDENCE}

Phone: +62 81329772630

E-mail: asif@stekom.ac.id

\section{PENDAHULUAN}

Bank memiliki data besar yang disimpan sebagai database dan diolah menghasilkan sebuah informasi yang berkaitan tentang nasabah, data tersebut dapat digunakan untuk menjaga hubungan bank dengan nasabah yang jelas agar dapat menentukan secara individual target penawaran produk bank, agar menjadi pelanggan dengan cara: menghubungi langsung https://doi.org/10.30743/infotekjar.v4i1.1574

\section{A B S T R A C T}

Strategi yang digunakan untuk telemarketing dengan melakukan media promosi, strategi tersebut merupakan sebuah cara pemasaran yang digunakan pihak bank, dalam penawaran produk kepada nasabah, bank, salah satu produk yang akan di tawarkan adalah deposito berjangka, pihak bank kesulitan dalam mengetahui kendala yang dialami nasabah dalam pengambilan keputusan untuk melakukan deposito terhadap bank, sehingga nantinya akan memiliki efek krisis keungan di bank. Telemarketing bank harus memiiki target terhadap nasabah, dimana nasabah yang memiliki potensi untuk bergabung salah satu produk bank, yaitu deposito dengan melihat data nasabah yang ada.

Dengan permasalahan yang ada akan diatasi dengan teknik datamining yang akan digunakan untuk penelitian ini adalah algoritma Nä̈ve Bayes dan algoritma genetika yang bertujuan untuk memprediksi keingian nasabah Telemarketing yang bersumber dari data public UCI Repsitory sehingga bank menawarkan sebuah produknya terhadap nasabah tepat sesai target. Pengujian Nä̈ve Bayes dengan hasil eksperimen akurasi $86,71 \%$ sedangkan pengujian cross validation menggunakan algoritma Genetika menghasilkan akurasi tinggi 90,27\%, Root membuktikan prediksi data time series metode Naïve Bayes dan Genetika menghasilkan akurasi sebesar 90,27\%, Sehingga dapat di simpulkan bahwa menggunakan algoritma Naive Bayes dan Genetika dapat mengoptimalkan dalam memprediksi keputusan klien Telemarketing tepat dalam penawaran deposito.

The strategy used for telemarketing by conducting promotional media, this strategy is a marketing method used by banks, in offering products to customers, banks, one of the products that will be offered is time deposits, the bank has difficulty in knowing the obstacles experienced by customers in making a decision to make deposits against the bank, so that later it will have the effect of a financial crisis at the bank. Telemarketing banks must have targets for customers, where customers have the potential to join one of the bank's products, namely deposits by looking at existing customer data.

With the existing problems will be overcome by the datamining technique that will be used for this research is the Nä̈ve Bayes algorithm and genetic algorithm which aims to predict the Telemarketing customers' sources sourced from public UCI Repsitory data so that the bank offers a product to the customer right at the target. Naïve Bayes test with experimental results of $86.71 \%$ accuracy while cross validation testing using Genetic algorithm produces high accuracy $90.27 \%$, Root proves the prediction of time series data Naïve Bayes method and Genetics produces an accuracy of $90.27 \%$, so it can be concluded that using the Naive Bayes algorithm and Genetics can optimize in predicting Telemarketing client decisions right in the deposit offer. dalam kontak pribadi, surat, telepon seluler, e-mail, maupun media lain dalam melakukan penawaran produk baru maupun pelayanan produk, media promosi ini disebut dengan promosi langsung, menginat promosi secara langsung banyak digunakan oleh Bank dan perusahaan asuransi dalam melakukan interaksi dengan pelanggan. [1]

Dahulu bank melakukan pemasaraan bertemu secara langsung dengan tujuan mempertahankan dan pencarian nasabah baru, tetapi beda dengan sekarang di saat teknologi pertumbuhan 
semakin besat, bank dapat memanfaatkan teknologi, salah satunya pemanfaatan telepon, media eletronik yang dapat melakukan komunikasi jarak jauh, dengan demikian bank dapat melakukan promosi kepada konsumen bank secara efektif daripada melakukan penawaran secara langsung maupun lewat brosur dan beretemu langsung.

Bank harus memiliki cara bagaimana mengetahui kendala nasabah telemarketing yang ingin melakukan deposito pada bank, agar bank terhindar dari ancaman krisis keuangan, dengan demikan Bank harus berupanya meningkatkan modal dengan cara menawarkan produk, salah satunya deposito jangka panjang terhadap nasabah.

Telemarketing bank harus memiliki dan membuat sebuah rencana untuk target nasabah mana yang berpotensi, agar dapat ditawarkan dan melakukan deposito dengan menganalisis data klien bank yang ada. [2],

Penulis ingin menguji keberhasilan telemarketing dengan cara melakukan prediksi keputusan nasabah dengan menerapkan mechine learning sehingga mendapatkan sebuah informasi dari pola yang ada dan mengekstraski informasi, salah satu algoritma klasifikasi yang digunakan yaitu Nä̈ve Bayes dengan metode algoritma sebagai yang menghasilkan klasifikasi nasabah bank telemarketing, data yang digunakan merupakan data primer dan skunder yang didapat dari data public UCI WEKA yang terdiri dari 45211 data dan 17 atribut, dari hasil penelitian diharapkan memberikan referensi mengenai akurasi dari klasifikasi nasabah bank telemarketing yang menggunakan algoritma naïve bayes dan penggunaan algoritma nä̈ve bayes yang disertai pemilihan variabel menggunakan algoritma genetika sebagai feature selection.

\section{STATE OF THE ART}

Metode Naïve Bayes juga digunakan pada penelitian Dwi Cahaya, P, B. (2016) dengan menerapkan metode Nä̈ve Bayes untuk mengetahui tingkat kesuburan, dikarenakan terdapat sebuahkasus yang di temui oleh peneliti dalam dua decade tingkat kesuburan (Fertilitas) mengalami penuruanan, yang menyebabkan kesuburan menurun salah satunya karena faktor lingkungan dan gaya hidup, misalkan alkohol, rokok yang dapat mempengaruhi kualitas seperma, sehingga peneliti menggunakan Nä̈ve Bayes untuk memprediksi faktor yang sangat berpengaruh didalam penentuan kesuburan, di dalam pengklasifikasi masih terdapat kekurangan sehingga peneliti berusaha untuk meningkatkan dengan cara mengoptimalkan kinerja metode Nä̈ve Bayes dengan menambahkan Algoritma Genetika yang awal mula result $97,66 \%$ menjadi $99,33 \%$ [3]

Risa Wati (20016) membahas tentang bagaimana mendapatkan sebuah klasifikasi yang tepat untuk menentukan opini positif dan negatif dari hasil riview kualitas layanan maskapai, dengan menggunakan algoritma Nä̈ve Bayes tetapi dirasa masih memiliki kelemahan untuk pemilihan featur sehingga penulis menggunakan algoritma genetika yang merupakan salah satu algortma optimasi dengan nilai awal $60,00 \%$ menjadi $89,50 \%$. [4]

Penelitian yang dilakukan oleh Oman Somantri dan Mohammad Khambali (2017) dengan judul "Feature Selection Klasifikasi Kategori Cerita Pendek Menggunakan Nä̈ve Bayes dan Algoritma Genetika" dapat disimpulkan bahwa penelitian tersebut penulis membahas tentang bagaimana menentukan cerpen yang sesuai dengan usia dan keinginan pembaca, sehingga peneliti mengusulkan untuk membuat sistem pengambil keputusan agar dapat mengklasifikasi sesuai jenis dan katagori cerpen, pada penelitian ini penulis menggunakan metode algoritma Nä̈ve Bayes dikarenakan metode tersebut sesuai untuk mengklasifikasi jenis katagori cerpen, penulis juga melakukan percobaan dalam optimasi metode tersebut dikarenakan hasil dari akurasi pengujian metode Nive Bayes masih kurang, sehingga peneliti menggunakan Algoritma Genetika sebagai feature selection untuk membantu mengoptimalkan hasil akurasi yang bermula dari $78,59 \%$ menjadi $84,29 \%$, sehingga dapat ditarik kesimpulan penggunakan algoritma Genetika dan Nä̈ve Bayes dapat digunakan untuk penentuan cerpen sesuai minat baca dan usia [5].

Penelitian Yaning wu, Song Huang dkk (2017) Prediksi kerusakan perangkat lunak berperan penting dalam mengidentifikasi modul-modul yang paling rusak sebelum pengujian perangkat lunak. Cukup banyak peneliti telah melakukan upaya besar untuk meningkatkan prediksi ketepatan. Namun, masalah data historis yang tidak memadai masih tersedia untuk dalam atau lintas proyek tetap tidak terselesaikan. Lebih lanjut, adalah praktik umum untuk menggunakan fungsi kerapatan probabilitas untuk fungsi normal distribusi dalam klasifikasi Nä̈ve Bayes (NB). Namun demikian, setelah melakukan tes Kolmogorov Smirnov, Kami menemukan bahwa 21 metrik perangkat lunak utama tidak terdistribusi secara normal pada tingkat signifikansi 5\%. Oleh karena itu, makalah ini mengusulkan classifier Bayes baru, yang mengembangkan classifier NB menjadi non-normal fungsi difusi informasi, untuk membantu memecahkan masalah kurangnya data pelatihan yang sesuai untuk yang baru proyek. Kami melakukan tiga percobaan pada 34 set data yang diperoleh dari 10 proyek sumber terbuka, hanya menggunakan Masing-masing 10\%, 6,67\%, 5\%, 3,33\%, dan $2 \%$ dari total data untuk pelatihan. Empat klasifikasi terkenal Algoritma juga termasuk untuk perbandingan, yaitu Regresi Logistik, Nä̈ve Bayes, Random Tree dan Mendukung Mesin Vektor. Semua hasil eksperimen menunjukkan efisiensi dan kepraktisan yang baru penggolong. [6]

Penelitian S. A. Mustofa, Aida, dkk (2019) membahas tentang teknik bagaimana Diagnosis penyakit Parkinson yang dilakukan oleh spesalis melibatkan beberapa pemeriksaan pemikiran kita, dan fisik. Spesialis menganalisa sejumlah gejala dan tanda ketika memriksa kondisi sistem saraf seseorang, Diagnosa dengan cara peninjauan literature medis dan faktor genetik orang yang menderita penyakit parkinson. Cara untuk mengatasi diagnosis terkini untuk penyakit Parkinson bergantung pada analisis gangguan suara. Metodologi ini mencakup penggalian set fitur suara orang yang direkam kemudian dimemanfaatkan untuk mecin learning, dimana teknik tersebut digunakan untuk mengidentifikasi kasus Parkinson yang benar berdasarkan suara seseorang. Penulis mencoba untuk meningkatkan diagnosis penyakit Parkinson dengan menguji beberapa evaluasi fitur dan metode mecin learning salah satunya dengan pemanfaat data mining klasifikasi berdasarkan analisis gangguan suara. Tujuan dari penelitian ini adalah untuk menemukan solusi optimal dalam mengatasi masalah tersebut dengan mengusulkan Pendekatan Evaluasi Fitur Berganda (MFEA) baru dari sistem multi-agen dan menerapkan lima skema klasifikasi independen diantaranya meliputi: Decision Tree, Naive Bayes, Neurel Network, Randem Forests, dan Support Vector Machine pada diagnosis Parkinson sebelum dan sesudah menerapkan MFEA, setelah itu mengevaluasi akurasi diagnosis hasil. Metodologi tes meliputi 10 kali lipat validasi silang untuk mengevaluasi pembelajaran metode ods dan lacak variasi dalam kinerja mereka. Hasil pengujian menunjukkan bahwa MFEA dari sistem multi-agen menemukan serangkaian fitur terbaik dan meningkatkan kinerja klasifikasi. Tingkat rata-rata peningkatan dalam akurasi diagnostik dari klasifikasi adalah Dicision Tree $10,51 \%$, Nalve Bayes 15,22\%, Neural Network 9,19\%, Random 
Forests 12,75\%, dan Support Vector Machine 9,13\%. Ini hasil menunjukkan bahwa MFEA membuat peningkatan yang signifikan pada hasil diagnosis klasifikasi, sehingga dapat disimpulkankan bahwa metode yang tepat untuk menganalisis penyakit parkison adalah Naïve bayes, dikarenakan dari hasil ujian metode tersebut mendapatkan akurasi yang paling tinggi dengan akurasi 15,22\%. [7]

Penelitian H. Muhammad, C. A. Prasojo, dkk (2017) membahas tentang optimasi Nä̈ve Bayes Classifier dengan PSO dari data iris. Penelitian tersebut melakukan klasifikasi dengan cara pembobotan atribut yang timal menggunakan PSO. Hasil diperoleh dari nilai fitness tertinggi, dan dilakukan 2 pengujian dengan jumlah partikel serta kombinasi parameter, jumlah partikel yang diuji 10 hingga 50 dengan pengujian 3 kali dengan hasil nilat rata-rata fitness tertinggi 97,39 dengan partikel 50, pada pengujian kombinasi parameter, membangkitkan nilai kombinasi dengan cara random dan diuji sebanyak 3 kali, dengan hail fitness 97,39 [8]

Penelitian Admaja dwi herlambang, S. H. Wijoyo (2019) melakukan penelitian di SMK TIK dan membahas tentang klasifiasi sumber belajar mata pelajaran produktif dari media internet, penelitian tersebut melakukan klasifikasi berdasarkan kreteria ciri esensial setiap mata pelajaran produktif di SMK TIK, pengelompokkan dengan algoritma Naive Bayes yang digunakan untuk dokumen teks dan menganggap semua atribut tidak berhubungan, Tujuan penelitian ini adalah untuk mendeskripsikan hasil klasifikasi dan evaluasi kualitas klasifikasi sumber belajar berbasis teks dengan menggunakan algoritma Nä̈ve Bayes dan pengujian menghasilkan nilai akurasi tertinggi $81,48 \%$, sedangkan nilai akurasi terendah sebesar 79,63\%. [9]

Dari kajian relevan yang ada, terdapat perbedaan indicator Age, Kridit (Default), Housing, Loan, Marital, Education, Contact, Balance, Duration, Campaign, Pdays, Previous, Putcome, Job, Serta Label Yes atau no, dan kasus dengan penerapan algoritma Naïve Bayes, shingga penulis menarik kesimpulan bahwa dari penelitian yang ada Nä̈ve Bayes merupakan metode yang cepat dalam melakukan perhitungan, agoritma yang sederhana dan akurasi yang tinggi namun memiliki kelemahan pada seleksi atribut sehingga peneliti ingin memperbaiki metode tersebut dengan menerapkan algoritma Genetika mampu menjadi seleksi fitur untuk meningkatkan hasil dari proses metode Nä̈ve Bayes.

\section{LANDASAN TEORI}

\section{Nä̈ve Bayes}

Naïve Bayes merupakan algoritma klasifikasi yang terbukti memiliki akurasi dan kecepatan yang tinggi ketika diaplikasikan pada database yang besar dan metode ini digunakan dalam statistika untuk menghitung peluang dari sebuah hipotesis berdasarkan atribut, kelas dan nilai probabilitas tertinggi yang dimiliki sebuah database [10], dengan rumus:

$P(H \mid X)=\frac{P(X \mid H) \cdot P(H)}{P(X)}$

Dimana:

$\mathrm{X}$ : Data yang belum diketahui kelasnya

$\mathrm{H}$ : Hipotesis data $\mathrm{X}$ merupakan suatu kelas spesifik

$\mathrm{P}(\mathrm{H} \mid \mathrm{X})$ : Probabilitas hipotesis H berdasarkan kondisi X

$\mathrm{P}(\mathrm{H})$ : Probabilitas hipotesis $\mathrm{H}$

$\mathrm{P}(\mathrm{X} \mid \mathrm{H})$ : Probabilitas X Berdasarkan kondisi H

$\mathrm{P}(\mathrm{X})$ : Probabilitas dari X

Dapat disederhanakan sebagai berikut :

$\mathrm{P}(\mathrm{H} \mid \mathrm{X})=\mathrm{P}(\mathrm{X} \mid \mathrm{H}) \mathrm{P}(X)$
Naïve Bayes terdaapat kelemahan dalam penentuan atribut, dimana masih terjadi kesalahan sehingga kurang optimal dalam menentukan hasil estimasi probabilitas, untuk mengatasi tersebut diperlukan cara dengan metode pembobotan yang menghasilkan peningkatan akurasi dari metode Naïve Bayes [11]

\section{Fiture Selection}

Dalam penggunaan Mechine Learning terdapat proses feature selection untuk pembelajaran algoritma, akurasi didapatkan dari kontribusi dimensi angka yang sedikit dari subset dalam proses feature selection akan memfilter sisa dari dimensi yang tidak berkepentingan sehingga akan meningkatkan performa dan akurasi dari sebuah metode algoritma [12]

\section{Optimasi}

Optimasi merupakan sebuah proses yang digunakan untuk menyelesaikan masalah agar mendapatkan kondisi yang paling menguntungkan dari sudut pandang, masalah tersebut berkaitan dengan varibel dari kumpulan data yang berkaitan. Yang di maksud dengan kondisi yang paling menguntungkan merupakan pencarian nilai minimum maupun maksimum tergantung yang diinginkan [13].

\section{Optimasi}

Optimasi merupakan sebuah proses yang digunakan untuk menyelesaikan masalah agar mendapatkan kondisi yang paling menguntungkan dari sudut pandang, masalah tersebut berkaitan dengan varibel dari kumpulan data yang berkaitan. Yang di maksud dengan kondisi yang paling menguntungkan merupakan pencarian nilai minimum maupun maksimum tergantung yang diinginkan [13].

\section{Algortma Genetika}

Adalah salah satu algoritma pencarian dengan cara seleksi alam dan genetika alam, genetika dimulai dengan sekumpulan individu yang membentuk populasi, dan satu individu adalah satu solusi, dari populasi akan berubah menjadi iterasi baru, dan pada iterasi terakhir salah satu populasi akan kembali menjadi solusi yang terbaik untuk mengatasi masalah yang terjadi, sehingga dapat diproseskan perubahan yang terjadi [14] ,Trevino dan Falciani (2006) ada 7 tahap dalam penerapan algoritma genetika yaitu :

a. Membentuk populasi awal terdiri dari beberapa kromosom yang didalamnya memuat gen kromosom pada algoritma genetika yang digunakan untuk menunjukkan kandidat sekelompok gen yang dapat digunakan sebagai solusi permaslahan. Gen pada algoritma genetika berisi variabel yang ingin dioptimumkan, pada penelitian ini gen berisi variabel independen.

$$
P O P=\operatorname{round}\left\{\operatorname{random}\left(N_{\text {Ipop }}, N_{\text {Ibits }}\right)\right\}
$$

Dimana:

POP $=$ merupakan gen yang berisi pembulatan dari

$\left(N_{\text {Ipop }}\right) \quad=$ (jumlah populasi $)$

$\left(N_{\text {ibits }}\right) \quad=$ (jumlah gendalam tiap kromosom)

b. Masing-masing kromosom dalam populasi dievaluasi kemampuannya dengan menggunakan fungsi fitness. Pada penelitian ini fungsi fitnesnya berupa kesalahan klasifikasi. 
$a+2 b+3 c=30$

Keterangan:

$\mathrm{a}, \mathrm{b}, \mathrm{c}$, merupakan varuabel yang digunakan untuk gen-gen dalam membuat chromosome. Varibel a memiliki bilangan integer 0 sampai 30. b, c, dan d memiliki bilangan integer 0 sampai 10.

Rumus probabilitas

$$
P(i)=\frac{\text { Fitnes }(i)}{\text { Total Fitnes }}
$$

c. Ketika sebuah kromosom memiliki nilai fitness lebih optimum daripada nilai inisialnya, maka kromosom dihentikan, namun apabila tidak maka tahapan analisis dilanjutkan ke tahap 4. Nilai fitnes terkecil yang dipilih sebagai solusi permasalahan dari penelitian ini, karena fungsi fitnes yang digunakan adalah tingkat kesalahan klasifikasi.

$$
Q(i)=\frac{1}{\text { Fitness }(i)}
$$

d. Memilih kromosom dengan nilai fitnes yang optimum yang dijadikan orang tua.

$$
C i=C(n)+P(n+1)
$$

e. Mengkombinasikan informasi genetika yang ada dalam replikasi orang tua melalui pindah silang. Dua induk secara random dipilih dan digunakan untuk membentuk dua kromosom baru. bilangan acak $\mathrm{R}$ antara 0 sampai dengan 1 , bilangan acak dipilih sesuai dengan jumlah cromosom:

$$
R=R(i)
$$

f. Melakukan mutasi untuk memperkenalkan unsur gen baru pada kromosom secara acak.

$$
C[x-1]<R<C[x]
$$

g. Tahapan diulangi dari tahapan 2 sampai kromosom yang memberikan nilai fitnes paling optimum atau sudah mencapai konvergen [15].

\section{ANALISA DAN HASIL}

Penelitian ini melakukan eksperimen dengan maksud untuk mendapakan penunjang keputusan dalam memprediksi nasabah bank yang ingin membeli produk bank yaitu deposito dengan menggunakan metode Naïve Bayes dan di optimalkan dengan metode Genetika data yang akan digunakan merupakan data primer dan skunder yang didapat dari data public UCI WEKA dengan pengujian menggunakan tools Rapidmainer 9.0 adapun tahapan sebagai berikut:

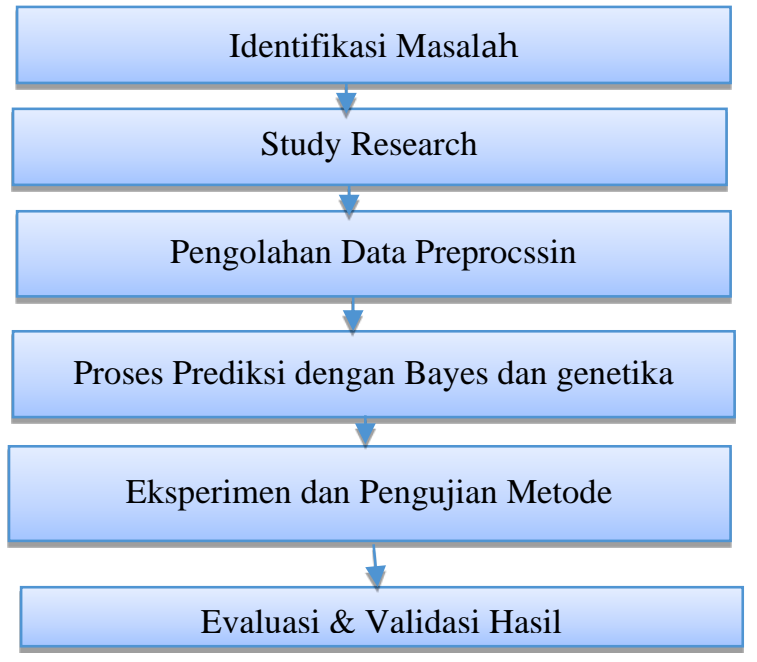

Gambar 1. Tahapan Penelitian

Dari gambar 1. Pengumpulan data ditentukan dengan pencrian data ke Website Uci Weka, dan data tersebut diintegrasikan kedalam data set, setelah pengumpualan data, pada pengolahan data, data yang sudah di jadikan data set dilakukan penyeleksian atribut, sehingga tertrasformasikan kedalam bentuk yang dibutuhkan, setelah data terkumpul dan diolah data akan diberi model dan membagi menjadi dua data training dan data testing, setelah mendapatkan metode penulis akan melakukan

Melakukan perhitungan dengan masingmasing Algoritma Nä̈ve Bayes dan Genetika yang akan diulang beberapa kali sampai menghasilkan nilai akurasi tertinggi. Tahap evaluasi merupakan tahap akhir dari rangkaian kegiatan penelitian ini. Setelah melakukan tahap pengujian model maka akan menghasilkan nilai akurasi dan AUC. Kemudian dari hasil itu dievaluasi, dari hasil evaluasi itu dapat ditarik kesimpulan dari hasil penelitian ini dapat dilihat pada gambar 2 .

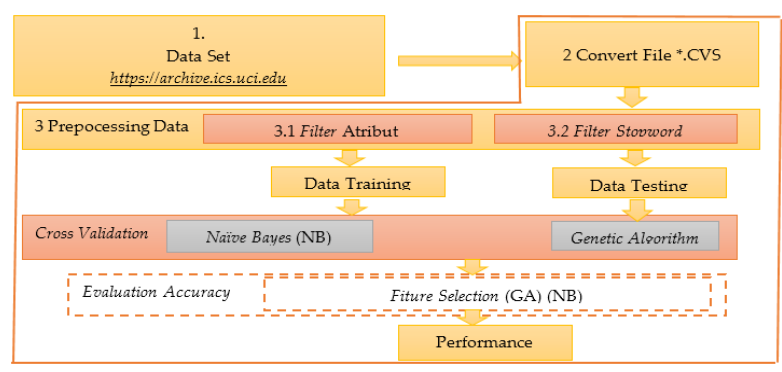

Gambar 2. Kerangka Pemikiran

Dari gambar 2. dapat dijelaskan kerangka pemikiran dalam penelitian ini tahapan awal melakukan pengumpulan data set yang didapat dari data public UCI WEKA dan di unduh pada laman https://archive.ics.uci.edu., dari data yang ada penulis merubah data yang awalmula berbentuk excel merubah menjadi *.cvs, tahapan selanjutnya melakukan praprocesing data dengan pemilihan atribut yang digunkan dan pembersihan tanda baca pada record atribut, penulis membagi data tersebut menjadi 2 kelompok yaitu: data training (data asli) dan testing (sampel data yang diambil dari data training tetapi record yang ada di atribut dirubah dan tidak diberikan label, kedua data tersebut akan diuji dan mendapatkan sebuah prediksi dari metode naïve bayes dan kombinasi naïve bayes genetika, hasil pengujian akan dibandingkan dengan melihat performance yang lebih tinggi. 


\section{Pengumpulan Data}

Data yang digunakan menggunakan data UCI WEKA, terdiri dari 4522 record, 16 atribut dan 1 atribut target, yang akan digunakan sebagai output data konsumen telemarketing, yang dapat dilihat pada tabel 1 .

Tabel 1.Tabel Data Konsumen Telemarketing

\begin{tabular}{|c|c|c|c|}
\hline No. & Variabel & Atribut & Keterangan \\
\hline . & $\mathrm{A}$ & Age & $\begin{array}{l}\text { Merupakan } r \\
\text { yang akan di katagorikut } \\
\text { menjadi } 3 \text { dengan } \\
\text { menggunakan referensi } \\
\text { WHO tentang klasifikasi } \\
\text { age. } \\
\text { Child }(<=14) \text {, young } \\
\text { - adult }(>=15 \text { and }<=49) \text {, } \\
\text { old }(>=50)\end{array}$ \\
\hline 2. & A2 & Job & $\begin{array}{l}\text { Atribut dari } \\
\text { dengan jenis pekerjaan } \\
\text { yang dikatagorikan: } \\
\text { "Admin", "unkown", } \\
\text { "unemployed", } \\
\text { "management", } \\
\text { "housemaid", } \\
\text { entrepreneur", "student", } \\
\text { "blue-collar", } \\
\text { "selfemployed", "retaired", } \\
\text { "technicion", "services". }\end{array}$ \\
\hline 3. & A3 & Maritial & $\begin{array}{l}\text { Atribut status perkawinan } \\
\text { dengan katagori: } \\
\text { "married", } \\
\text { "divorced","single". }\end{array}$ \\
\hline- & - & - & - \\
\hline 17. & A17 & Output & $\begin{array}{l}\text { Output }=\text { Atribut dengan } \\
\text { targen yang akan } \\
\text { mendepositokan, katagori } \\
\text { yaes atau no, dan data di } \\
\text { ubah menjadi numeric } \\
\text { untuk mempermudah } \\
\text { pengerjaan yaitu Yes }=2 \\
\text { dan No=1. }\end{array}$ \\
\hline
\end{tabular}

Untuk melakukan pengujian di persiapkan data yang akan digunakan dengan cara pengmabilan data secara acak

Tabel 2. Data Training

\begin{tabular}{|l|l|l|l|l|l|l|}
\hline \multicolumn{7}{|c|}{ Data Training } \\
\hline No. & 1 & 2 & 3 & - & - & 28 \\
\hline Age & 70 & 63 & 60 & - & - & 37 \\
\hline Job & Retired & Retired & Services & - & - & Entrepre \\
\hline Marital & Married & Married & Married & - & - & Married \\
\hline Education & Primary & Secondary & Tertiary & - & - & Secondary \\
\hline Balance & 324 & 1495 & 4256 & - & - & 2971 \\
\hline Housing & No & No & Yes & - & - & No \\
\hline Loan & No & No & No & - & - & No \\
\hline Contact & Celluler & Celluler & Celluler & - & - & Celluler \\
\hline Day & 15 & 16 & 16 & - & - & 17 \\
\hline Month & Nov & Nov & Nov & - & - & Nov \\
\hline Duration & 78 & 138 & 200 & - & - & 361 \\
\hline Campaign & 1 & 1 & 1 & - & - & 2 \\
\hline Pdays & 96 & 22 & 92 & - & - & 188 \\
\hline Previous & 7 & 5 & 4 & - & - & 11 \\
\hline Putcome & Success & Success & Success & - & - & other \\
\hline Y & No & No & Yes & - & - & No \\
\hline
\end{tabular}

Data tabel 2 merupakan data atribut dengan Age, Kridit (Default), Housing, Loan, Marital, Education, Contact, Balance, Duration, Campaign, Pdays, Previous, Putcome, Job, Serta Label Yes atau no, yang dipilih secara acak yanga akan dilakukan transformasi pada data yang telah dipilih sehingga sesuai dengan proses data mining dalam bentuk MS. Excel karena data akan digunakan dalam tools rapid miner dan di tentukan bebrapa atribut yang akan digunakan.

\section{Pengujian data dan hasil}

Pada tahap ini dilakukan pengujian data training sesuai tujuan penelitian yaitu untuk menerapkan teknik klasifikasi menggunakan metode optimasi naïve bayes dengan genetika untuk mendapatkan keputusan dalam penentuan nasabah untuk melakukan deposito.

Tabel 3. (a) Data Testing Dan (b) data Training

\begin{tabular}{|c|c|}
\hline \multicolumn{2}{|c|}{ Data Testing } \\
\hline No. & 1 \\
\hline Age & 22 \\
\hline Job & Student \\
\hline Marital & Single \\
\hline Education & Primary \\
\hline Balance & 3472 \\
\hline Housing & No \\
\hline Loan & No \\
\hline Contact & Celluler \\
\hline Day & 19 \\
\hline Month & Apr \\
\hline Duration & 529 \\
\hline Campaign & 1 \\
\hline Pdays & 181 \\
\hline Previous & 4 \\
\hline Putcome & Success \\
\hline Y & $? ? ? ? ?$ \\
\hline
\end{tabular}

(a) 


\begin{tabular}{|l|l|l|l|l|}
\hline \multicolumn{5}{|c|}{ Data Training } \\
\hline Indikator & \multicolumn{3}{|c|}{ No } \\
\cline { 2 - 5 } & 1 & 2 & - & 28 \\
\hline Age & 70 & 63 & & 37 \\
\hline Job & Retired & Retired & & Entre \\
\hline Marital & Married & Married & & Marr \\
\hline Education & Primary & Secondary & & $\begin{array}{l}\text { Seco } \\
\text { y }\end{array}$ \\
\hline Balance & 324 & 1495 & 2971 \\
\hline Housing & No & No & No \\
\hline Loan & No & No & No \\
\hline Contact & Celluler & Celluler & Cellu \\
\hline Day & 15 & 16 & 17 \\
\hline Month & Nov & Nov & Nov \\
\hline Duration & 78 & 138 & 361 \\
\hline Campaign & 1 & 1 & 2 \\
\hline Pdays & 96 & 22 & 188 \\
\hline Previous & 7 & 5 & & 11 \\
\hline Putcome & Success & Success & other \\
\hline Y & No & No & No \\
\hline
\end{tabular}

(b)

Tabel 3. Merupakan tabel training dan testing, tabel (a) menjadi tabel target yang akan diprediksi untuk mendapatkan sebuah label dari pengujian metode yang dapat dilihat pada tabel testing atribut y yang masih ditanyakan labelnya, (b) sebagai tabel asli atau tabel training, dari tabel tabel training akan dilakukan perhitungan masing-masing label dengan menggunakan kreteria yes dan no tahapan sebagai berikut:

a. Tahap 1 Menghitung masing-masing kelas dan label

$\mathrm{Y}(\mathrm{Y}=\mathrm{Yes})=19 / 28$

$\mathrm{y}(\mathrm{Y}=\mathrm{No})=9 / 28$

b. Tahap 2 Menghitung kasus yang sama dengan kelas yang sama

Tabel 3. (a) Pengujian atribut poutcome (b) Pengujian atribut previous (c) Data training

\begin{tabular}{|l|l|l|}
\hline No. & poutcome & y \\
\hline 1 & success & no \\
\hline 2 & success & no \\
\hline 3 & success & yes \\
\hline 4 & failure & no \\
\hline 5 & unknown & yes \\
\hline 6 & success & yes \\
\hline 7 & failure & no \\
\hline 8 & success & yes \\
\hline 9 & failure & yes \\
\hline 10 & unknown & yes \\
\hline- & - & - \\
\hline- & - & - \\
\hline 28 & other & No \\
\hline \multicolumn{3}{|l|}{} \\
\hline \multirow{3}{*}{ Hsl } & Success $=7$ & Yes $=19$ \\
\cline { 2 - 3 } & $7 / 19$ & No $=9$ \\
\hline & Success $=2$ & \\
\cline { 2 - 3 } Hsl & $2 / 9$ \\
\hline
\end{tabular}

(a)

\begin{tabular}{|l|l|l|}
\hline No. & previous & y \\
\hline 1 & 7 & no \\
\hline 2 & 5 & no \\
\hline 3 & 4 & yes \\
\hline 4 & 2 & no \\
\hline 5 & 0 & yes \\
\hline 6 & 2 & yes \\
\hline 7 & 5 & no \\
\hline 8 & 3 & yes \\
\hline 9 & 1 & yes \\
\hline 10 & 0 & yes \\
\hline- & - & - \\
\hline- & - & - \\
\hline 28 & 11 & No \\
\hline \multicolumn{3}{|l}{} \\
\hline \multirow{3}{*}{ Hsl } & $\begin{array}{l}\text { Previous } 4 \\
=3\end{array}$ & Yes $=19$ \\
\cline { 2 - 4 } $3 / 19$ & previous $=$ & No $=9$ \\
\hline \multirow{3}{*}{ Hsl } & 2 & $2 / 9$ \\
\cline { 2 - 3 } & \multicolumn{3}{|l}{} \\
\hline
\end{tabular}

(b)

\begin{tabular}{|c|c|c|c|c|c|}
\hline \multicolumn{2}{|c|}{ Atribut } & \multirow[b]{2}{*}{$\begin{array}{c}\text { Statu } \\
\text { s } \\
\text { Labe } \\
1 \\
\text { Yes } \\
\text { atau } \\
\text { No }\end{array}$} & \multicolumn{2}{|c|}{ Jumlah } & \multirow{2}{*}{$\begin{array}{c}\text { Hasi } \\
1\end{array}$} \\
\hline Nama & Nilai & & $\begin{array}{l}\text { Nilai } \\
\text { Atribu } \\
\mathrm{t}\end{array}$ & $\begin{array}{l}\text { Nilai } \\
\text { Labe } \\
1\end{array}$ & \\
\hline Pdays & \multirow{2}{*}{181} & Yes & 0 & 19 & $0 / 19$ \\
\hline Pdays & & No & 0 & 9 & $0 / 9$ \\
\hline $\begin{array}{l}\text { campaig } \\
\mathrm{n}\end{array}$ & \multirow{2}{*}{1} & Yes & 13 & 19 & $\begin{array}{l}13 / 1 \\
9\end{array}$ \\
\hline $\begin{array}{l}\text { campaig } \\
\mathrm{n}\end{array}$ & & No & 4 & 9 & $4 / 9$ \\
\hline duration & \multirow{2}{*}{529} & Yes & 0 & 19 & $0 / 19$ \\
\hline duration & & No & 0 & 9 & $0 / 19$ \\
\hline contact & \multirow{2}{*}{$\begin{array}{l}\text { cellula } \\
\mathrm{r}\end{array}$} & Yes & 19 & 19 & $\begin{array}{l}19 / 1 \\
9\end{array}$ \\
\hline contact & & No & 8 & 9 & $8 / 9$ \\
\hline Loan & \multirow[t]{2}{*}{ No } & Yes & 18 & 19 & $\begin{array}{l}18 / 1 \\
9\end{array}$ \\
\hline Loan & & No & 8 & 9 & $8 / 9$ \\
\hline Housing & \multirow[t]{2}{*}{ No } & Yes & 13 & 19 & $\begin{array}{l}13 / 1 \\
9 \\
\end{array}$ \\
\hline Housing & & No & 7 & 9 & $7 / 9$ \\
\hline Balance & \multirow{2}{*}{3472} & Yes & 0 & 19 & $0 / 19$ \\
\hline Balance & & No & 0 & 9 & $0 / 9$ \\
\hline Default & \multirow[t]{2}{*}{ No } & Yes & 19 & 19 & $\begin{array}{l}19 / 1 \\
9\end{array}$ \\
\hline Default & & No & 9 & 9 & $9 / 9$ \\
\hline $\begin{array}{l}\text { educatio } \\
\mathrm{n}\end{array}$ & \multirow[t]{2}{*}{$\begin{array}{l}\text { Primar } \\
\text { y }\end{array}$} & Yes & 1 & 19 & $1 / 9$ \\
\hline $\begin{array}{l}\text { educatio } \\
\mathrm{n}\end{array}$ & & No & 1 & 9 & $1 / 9$ \\
\hline Marital & \multirow[t]{2}{*}{ Single } & Yes & 9 & 19 & $9 / 19$ \\
\hline Marital & & No & 2 & 9 & $2 / 9$ \\
\hline Job & & Yes & 2 & 19 & $2 / 19$ \\
\hline
\end{tabular}

https://doi.org/10.30743/infotekjar.v4i1.1574 


\begin{tabular}{|l|l|l|l|l|l|}
\hline Job & $\begin{array}{l}\text { Studen } \\
\mathrm{t}\end{array}$ & No & 0 & 9 & $0 / 9$ \\
\hline Age & 22 & Yes & 0 & 19 & $0 / 19$ \\
\cline { 3 - 6 } Age & & No & 0 & 9 & $0 / 9$ \\
\hline
\end{tabular}

(c)

Tabel 3 merupakan perhitungan kasus yang sama dengan kelas sama dengan contoh tabel (a) menghitung jumlah atribut putcome dengan kasus success dan kelas yes, serta kasus success dan kelas no. tabel (b) menghitung jumlah atribut previous dengan kasus 4 dan kelas yes, serta kasus 4 dan kelas no. tabel (c) merupakan kelanjutan perhitungan atribut yang lain sampai semua atribut dihitung.

c. Tahap 3 Mengalikan semua hasil kasus

$7 / 192 / 9 \times 3 / 19.0 / 9 \times 0 / 19 \times 0 / 9 \times 13 / 19 \times 4 / 9 \times 0 / 19 \times$

$0 / 9 \times 19 / 19 \times 8 / 9 \times 18 / 19 \times 8 / 9 \times 13 / 19 \times 7 / 9 \times 0 / 19 \times 0 / 9$

x $19 / 19 \times 9 / 9 \times 1 / 19 \times 1 / 9 \times 9 / 19 \times 2 / 9 \times 2 / 19 \times 0 / 9 \times 0 / 19$

$\mathrm{x} 0 / 9=0$

Dari hasil perhitungan dengan metode naïve bayes menghasilkan nilai 0 yang memiliki arti bahwa data testing akan diprediksi (Yes)

Pengujiian model yang dilakukan dalam memprediksi nasabah bank dengan algortima naïve bayes dengan bantuan tools rapidminer dapat menentukan nilai accuracy dan AUC. Didalam proses penentuan nilai accuracy penulis menggunakan cross validation dengan desaign model Gambar 3 :

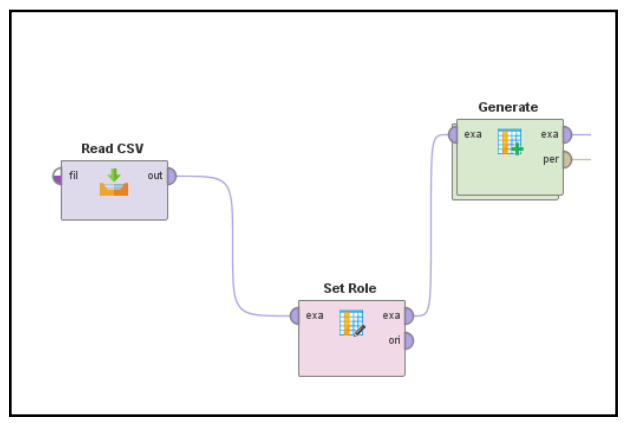

\section{Gambar 3. Model Validasi}

Pada penelitian ini penulis akan menerapkan metode naïve

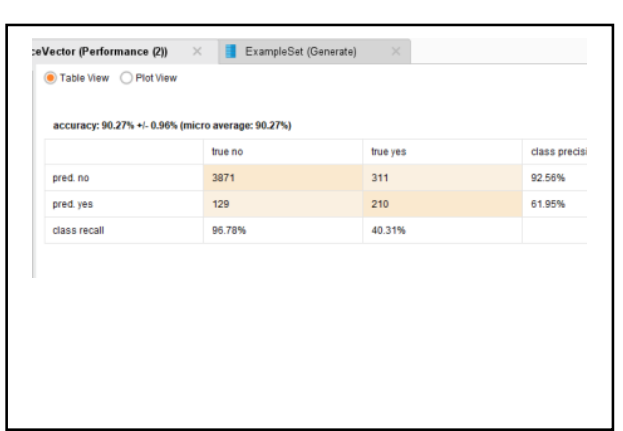

bayes

sebagai pengambil keputusan untuk menentukan nasabah bank yang akan membeli produk deposito bank pada gambar 3 .

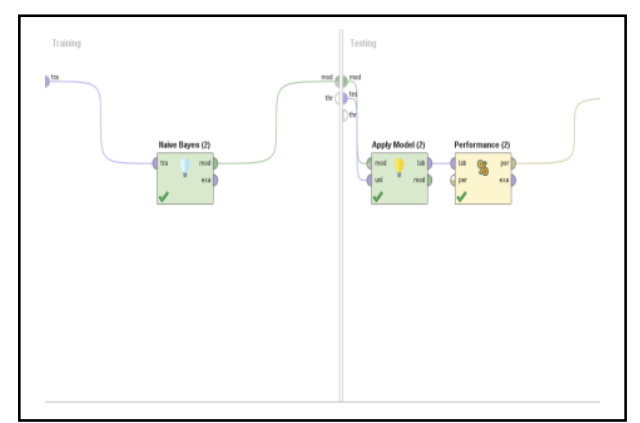

Gambar 4. Pengujian data menggunakan metode Nä̈ve Bayes

Sehingga dari pengujian tersebut didapatkan sebuah hasil yang berupa accuracy, precision, dan nilai recall dari data training dengan bantual tools rapidmainer, yang dapat dilihat pada gambar 5 .

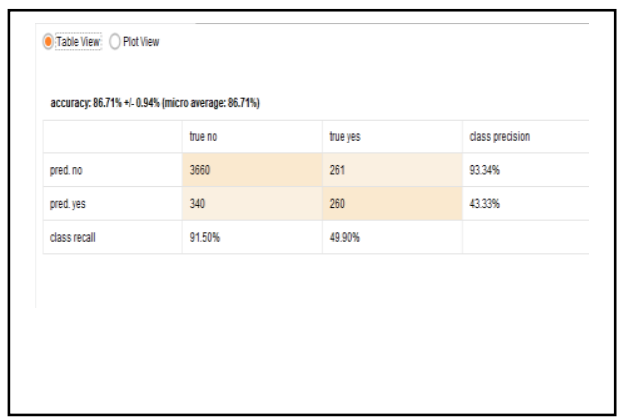

Gambar 5. Hasil Accuray dari pengujian Metode

Dari gambar 5. Dapat disimpulkan bahwa dari pengujian menggunakan metode naïve bayes mendapatkan akurasi $86,71 \%$, dengan demikian peneliti melakukan optimasi dengan metode Genetika.

Pengujian metode nä̈ve bayes dengan genetika sebagai untuk menentukan nasabah bank yang akan membeli produk deposito pada gammbar 6 .

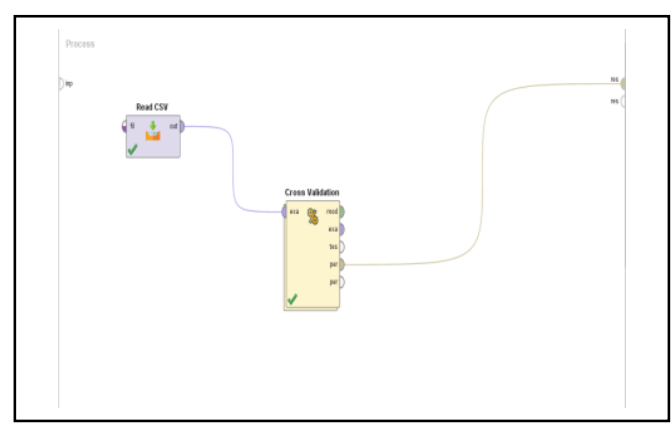

Gambar 6. Pengujian data menggunakan metode Nä̈ve Bayes dan Genetika

Sehingga dari pengujian tersebut didapatkan sebuah hasil yang berupa accuracy, precision, dan nilai recall dari data training dengan bantual tools rapidmainer, yang dapat dilihat pada gambar 7.

Dari gambar 7. menunjukkan bahwa pengujian dengan algoritma Naive Bayes dan Genetika menunjukkan bawa mengalami peningkatan accuray dengan peningkatan $4 \%$ dari hasil algoritma Naive Bayes, acucuracy Naive bayes dan Genetika 90.27\% dengan demikian peneliti melakukan optimasi dengan metode Genetika. 
Input : NB(C, D)

$V \leftarrow$ Banyaknya atribut Nasabah Bank (17 jenis)

$N \leftarrow$ Banyaknya Kelas (2 Kelas)

For each $c \in \mathrm{C}$ do

$N_{c} \leftarrow$ Count Docs In Class $(D, c)$

prior $[c] \leftarrow N c / N$

$L_{c} \leftarrow$ Count Case of All Docs in Class $(D, c)$

For each $t \in \mathrm{v} d o$

$T_{c t} \leftarrow$ Count Case of Therm $\left(L_{c}, t\right)$

For each $t \in$

do condprob $[t][c] \leftarrow\left(\frac{t_{c t}+1}{\left(\Sigma_{t^{\prime}}-\left(T_{c t^{\prime}}+1\right)\right.}\right)$

$V$, prior, condprop

$N B(C, V$, Prior, condprob, $d)$

$W \leftarrow$ Extract Case From Doc $(V, d)$

\section{For each $c \in C$ do}

Score $[c] \leftarrow \log$ prior $[c]$ do

Score $[c]+\leftarrow$ Log condprob $[t][c]$

Return $\arg \max _{c \in C}$ Score $[c]$

\section{Keterangan :}

Untuk masing-masing atribut Yes merupakan himpunan Kelas, lalu menghitung jumlah Yes didalam kelas yang sama di keselurahan atribut, sehingga mendapatkan nilai prior yes dan kasus yang sama, hitung semua kelas dalam 1 kasus, menghitung jumlah No didalam kelas yang sama pada keseluruhan atribut, sehingga mendapatkan nilai prior no pada kasus yang sama, menghitung kondisi probabilitas Yes dan No dan mendapatkan kelompok atribut yang dipilih dan dilakukanukan secara berula

Dilakukan penilain jika $\mathrm{v} \leq$ titik potong di interval, nilai $\mathrm{v}$ masuk interval pertama sehingga frekuensi di interval tersebut ditambah. Lakukan penambahan count [c][label kelas] dan rekam interval keberapa yang mengalami perubahan, Jika $v>$ titik potong di interval pertama maka lanjut ke interval selanjutnya dan lakukan hal yang sama di poin 10. Jika nilai error tidak berubah dari error sebelumnya maka keluar dari sistem dan jika berubah maka keadaan TRUE terpenuhi.

e. Langkah-langkah penyelesaian dengan algoritma genetika:

Membangkitkan Populasi

$$
/ \text { POP }=\operatorname{round}\left\{\operatorname{random}\left(N_{\text {Ipop }}, N_{\text {Ibits }}\right)\right\}
$$

POP = merupakan gen yang berisi
pembulatan dari bilangan acak yang dibangkitkan

$\left(N_{\text {Ipop }}\right) \quad=\quad$ (jumlah populasi)

$\left(N_{\text {ibits }}\right)=\quad$ (jumlah gendalam tiap kromosom $)$

Prediksi (Yes) dan (No), dengancara dalam menyelesaikan masalah kombinasi. Pada persamaan $a+2 b+3 c=30$, kita cari nilai $\mathrm{a}, \mathrm{b}, \mathrm{c}$, dan d yang memenuhi persamaan diatas. menggunakan algoritma genetika untuk menyelesaikan permasalahan.

$$
\mathrm{c} 1=\text { [07_13_17] }
$$$$
\mathrm{c} 2=\left[03 \_05 \_07\right]
$$

Evaluasi nilai fitnes

Dengan rumus yaitu $a+2 b+3 c=30$, akan menghasilkan nilai fitnes pada setiap kromosom,

$$
\begin{aligned}
& \text { Fitnes } C 1=1 /(1+|(a+3 b+2 c)-30|) \\
& \quad=1 /(1+\mid((7+(3 * 13)+(2 * 17)-30 \mid) \\
& \quad=0,019608
\end{aligned}
$$

$$
\begin{aligned}
& \text { Fitnes } C 2=1 /(1+|(a+3 b+2 c)-30|) \\
& \quad=1 /(1+\mid((3)+(3 * 5)+(2 * 7)-30 \mid) \\
& \quad=0,333333
\end{aligned}
$$
0,352941

Total nilai fitnes $\mathrm{C} 1+\mathrm{C} 2=0,019608+0,333333=$

Rumus untuk mencari probabilitas: $\mathrm{P}[\mathrm{i}]=$ fitness $[\mathrm{i}]$ / total fitness

$$
\begin{aligned}
& P[1]=0,019608 / 0,352941=0,055556 \\
& P[2]=0,333333 / 0,352941=0,944444
\end{aligned}
$$

Probabilitas diatas dapat kita lihat kalau kromosom ke 2 yang mempunyai fitness paling besar maka kromosom tersebut mempunyai probabilitas untuk terpilih pada generasi selanjutnya lebih besar dari kromosom lainnya.

Menentukan kromoson induk

Untuk proses seleksi kita gunakan roulete wheel, untuk itu kita harus mencari dahulu nilai kumulatif probabilitasnya:

$$
\begin{aligned}
& \mathrm{C}[1] \quad=\quad 0,055556 \\
& \mathrm{C}[2]=0,055556+0,944444=1
\end{aligned}
$$

Langkah selanjutnya adalah dengan menggunakan bilangan acak $\mathrm{R}$ antara 0 sampai dengan 1, bilangan acak dipilih sesuai dengan jumlah cromosom:

$$
\begin{aligned}
& R[1]=0,066667 \\
& R[2]=0,25
\end{aligned}
$$

Memilih kromosom ke $\mathrm{x}$ sebagai parent dengan syarat $\mathrm{C}[\mathrm{x}-1]<\mathrm{R}<\mathrm{C}[\mathrm{x}]$. Angka acak $\mathrm{R}[1]<$ nilai kumulatif dari $\mathrm{C} 2$, sehingga $\mathrm{C} 2$ nanti akan dilakukan crossover dengan $\mathrm{C} 1$. Hasil seleksi

Roullete Wheel pada populasi ini untuk crossover menjadi:

C1 Menjadi C2 $=$ [03_05_07]

C2 Menjadi C2 $=$ [03_05_07]

kromosom-kromosom ini akan mengalami proses yang sama seperti generasi sebelumnya yaitu proses evaluasi, seleksi, crossover dan mutasi yang kemudian akan menghasilkan kromosom-kromosom baru untuk generasi yang selanjutnya. Proses ini akan berulang sampai sejumlah generasi yang telah ditetapkan sebelumnya.

Pengujian Cross Validation didapatkan akurasi 90,27\% dibanding dengan akurasi pada pengujian Nä̈ve Bayes dengan nilai $86,71 \%$, algoritma genetika berhasil mengoptimalkan metode Nä̈ve Bayes sehingga metode Nä̈ve Bayes dan genetika akan digunakan untuk penentuan nasabah bank yang akan membeli produk deposito. Dan dapat dirumuskan dengan accuracy dari confusion matrix adalah sebagai berikut:

$$
\text { a) } \begin{aligned}
\text { Accuracy } & =\frac{T P+T N}{T P+T N+F P+F N} \\
& =\frac{210+3871}{210+3871+311+129}=\frac{4081}{4521} \\
& =0,9027=90,27 \%
\end{aligned}
$$


b) Sensitivity $=\frac{T P}{T P+F P}$

$$
\begin{aligned}
& =\frac{210}{210+129}=\frac{210}{339} \\
& =0,6195=61,95 \%
\end{aligned}
$$

c) Specificity $=\frac{T N}{T N+F P}$

$$
\begin{aligned}
& =\frac{3871}{3871+311}=\frac{3871}{4182} \\
& =0,9256=92,56 \%
\end{aligned}
$$

d) PPV

$$
=\frac{T P}{T P+F P}
$$$$
=\frac{210}{210+311}=\frac{210}{521}
$$$$
=0,4031=40,31 \%
$$

e) $\mathrm{NPV}=\frac{T N}{T N+F N}$

$$
\begin{aligned}
& =\frac{3871}{3871+129}=\frac{3871}{4000} \\
& =0,9678=96,78 \%
\end{aligned}
$$

Hasil dari pengujian mendapakan sebuah kurva roc pada gambar 8. Dimana curva tersebut mengepresikan Confusion Matrix dari sebuah tabel data set.

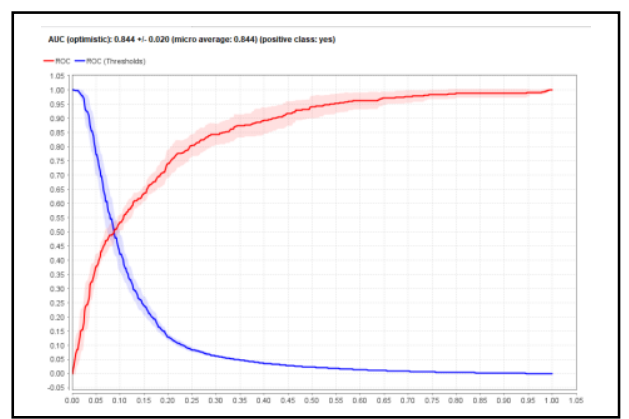

Gambar 8. Kurva Roc Naïve Bayes dan Genetika

Gambar 8. Merupakan kurva ROC yang memberikan penjelasan tentang hubungan uji sensitifitas dengan spesifisitas, pada kurva roc dapat diketahui terdapat 2 sumbu, yaitu sumbu $\mathrm{x}$ dan $\mathrm{y}$, dengan persamaan y (TP) True Positive dan x (FP) False Positive, sedangan warna biru menunjukan ROC (Thershold) dan di nyatakan sebagai (TP) dikarenakan memiliki nilai 1 sedangkan warna merah disebut ROC dinyatakan sebagai (FP) karena memiliki titik 0, pada ROC (Thershold) memiliki titik 1 dan ROC memiliki titik 0 menunjukkan bahwa prediksi dinyatakan tidak benar (false), jika nilai titik anatara ROC (Thershold) dan ROC $(0,1)$ maka prediksi dinyatakan sempurna atau benar (True) baik kasus positif maupun negatif

\section{KESIMPULAN DAN SARAN}

Berdasarkan dari hasil pengujian metode, didapatkan sebuah model untuk melakukan optimasi data dengan menggunakan algoritma Genetika terbukti dengan peningkatan hasil akurasi dari klasifikasi Penentuan Nasabah Bank yang akan Berdeposito dengan feature selection, dengan hasil nilai $86,71 \%$ menjadi $90,27 \%$, Peningkatan akurasi yang dihasilkan tentunya belum sempurna, sehingga perlu adanya upaya-upaya lain dalam meningkatkan akurasi yang dihasilkan.

Terdapat beberapa saran untuk penelitian selanjutnya, yaitu sebagai berikut. Perlu dilakukan eksperimen dengan menggunakan algoritma optimasi lain seperti ACO, PSO, dan yang lainnya. Pemilihan parameter untuk optimasi juga sangat berpengaruh terhadap tingkat akurasi yang dihasilkan, sehingga perlu adanya penetapan parameter yang sesuai dengan model yang diusulkan. Selain itu, terdapat optimasi peningkatan akurasi kembali dengan menggunakan metode lain yang sesuai, sehingga dimungkinkan untuk diterapkannya konsep model hybrid lain.

\section{DAFTAR PUSTAKA}

[1] C. Ou, C. Liu, J. Huang and N. Zhong, "On Data Mining for Direct Marketing," Springer-Verlag Berlin, p. PP. 491498., 2003.

[2] D. T. LAROSE, Data Mining Methods and Models, ISBN13 978-0-471-66656-1, America: Department of Mathematical Sciences Central Connecticut State University, 2006.

[3] D. C. P. Buani, "Optimasi Algoritma Naïve Bayes dengan Menggunakan Algoritma Genetika untuk Prediksi Kesuburan (Fertility)," Evolusi, vol. 4, no. 1, pp. 54 - 63, 2016.

[4] R. Wati, "Penerapan Algoritma Genetika Untuk Seleksi Fitur Pada Analisis Sentimen Review Jasa Maskapai Penerbangan Menggunakan Naive Bayes," Evolusi, vol. 4, no. 1, pp. 25 - 31, 2016.

[5] O. Sumantri and M. Kambali, "Feature Selection Klasifikasi Kategori Cerita Pendek Menggunakan Naïve Bayes dan Algoritme Genetika," JNTETI, vol. 6, no. 3, pp. 301 - 3016, 2017.

[6] Y. Wu, S. Huang, H. Ji, C. Zheng and C. Bai, "A Novel Bayes Defect Predictor Based on Information Diffusion Function," Knowledge-Based Systems, vol. 144, pp. 9-15, 2017.

[7] S. A. Mostafa, A. Mustapha and M. a. Muhammad, "Examining multiple feature evaluation and classification methods," Cognitive Systems Research, vol. 54, pp. 90-99, 2019.

[8] H. Muhammad, C. A. Prasojo, N. A. Sugianto, L. Surtiningsih and I. Cholissodin, "Optimasi Naïve Bayes Classifier Dengan Menggunakan Particle Swarm Optimization Pada Data Iris," Jurnal Teknologi Informasi dan Ilmu Komputer (JTIIK), vol. 4, no. 3, pp. 180-184, 2017.

[9] A. D. Herlambang and S. H. Wijoyo, "Algoritma Naïve Bayes Untuk Klasifikasi Sumber Belajar Berbasis Teks Pada Mata Pelajaran Produktif Di Smk Rumpun Teknologi Informasi Dan Komunikasi," Jurnal Teknologi Informasi dan Ilmu Komputer (JTIIK) , vol. 6, no. 4, pp. 431-436 , 2019.

[10] B. "Penerapan Algoritma Naïve Bayes Untuk Mengklasifikasi Data Nasabah Asuransi," TECHSI : Jurnal PenelitianTeknik Informatika, vol. 3, no. 2, pp. 127 - 146, 2013.

[11] J. C. M. J. C. N. A. Zaidi, "Alleviating Naive Bayes Attribute Independence Assumption byAttributeWeighting," Journal of Machine Learning Research, vol. 1, no. 14, pp. 1947 - 1988, 2013.

[12] S. Kusuma dewi, Artificial Intelligent., Yogyakarta: Graha Ilmu, 2003.

[13] Z. Zukhri, Algoritma Genetika Metode Komputasi untuk Menyelesaikan Maslah Optimasi., Yogyakarta: Andi Offset, 20014. 
[14] A. M. D. Anita, Konsep Kecerdasan Buatan, Yogyakarta: Andi Offset., 2006.

[15] V. d. F. Trevino, "GALGO: an R package for multivariate variable selection using genetic algorithms," Bioinformatics, vol. 22, p. 1154-1156., 2006. 